\title{
CD44 expression during tumor progression of follicular lymphoma
}

\author{
MORIHIRO HIGASHI, YOSHIKI SUGAYA, SATOSHI SOETA, AKIRA YOKOTA, \\ GENICHIRO ISHII and KENICHI HARIGAYA
}

\begin{abstract}
Department of Molecular and Tumor Pathology, Chiba University Graduate School of Medicine, 1-8-1 Inohana, Chuo-ku, Chiba 260-8670, Japan
\end{abstract}

Received March 19, 2009; Accepted May 18, 2009

DOI: $10.3892 /$ or_00000546

\begin{abstract}
Follicular lymphoma often progresses to diffuse type lymphoma. To elucidate the mechanisms of the diffuse evolution of follicular lymphoma, we investigated the expression pattern of CD44 in 28 cases of follicular lymphomas (FLs) using an immunohistochemical method and semi-quantitative PCR-Southern blot analysis. The FLs were divided into four groups: i) intrafollicular (IF); ii) infiltrative (INF); iii) partially follicular (PF); and iv) minimally follicular (MF), according to the histological classification by Lukes and Collins. Immunohistochemical analysis of CD44 using antibodies against CD44 common (CD44C) epitopes showed that CD44 was expressed in the diffuse area in the INF ( $0 / 8$ cases), PF (12/12 cases), and MF (2/2 cases) lymphomas, whereas CD44 was not expressed in the lymphoma cells within the area of follicular growth of IF ( $0 / 6$ cases) and INF (0/8 cases). Semi-quantitative PCRSouthern blot analysis showed that CD19-selected B cells from the FLs were expressed as a product of 482 base pairs (bp) corresponding to a CD44 standard form (CD44s) $(5 / 5$ cases). Additionally, the lymphoma cells from the PF were expressed as products of 600 and $1100 \mathrm{bp}$ and the cells from MF were expressed as products of 600,900 , and $1100 \mathrm{bp}$ with the CD44 exon 10 or 11 probes. The results indicated that the expression of CD44s and CD44 variants containing exon 10 and 11 were up-regulated according to the diffuse evolution of the follicular lymphoma.
\end{abstract}

\section{Introduction}

Adhesive protein CD44 is a transmembrane glycoprotein with phosphorylation sites in its cytoplasmic domain $(1,2)$. CD44 is expressed on many different cell types including hematopoietic cells, fibroblasts, some epithelial and endo-

Correspondence to: Dr Kenichi Harigaya, Department of Molecular and Tumor Pathology, Chiba University Graduate School of Medicine, 1-8-1 Inohana, Chuo-ku, Chiba 260-8670, Japan

E-mail: mhigashi@pa2.so-net.ne.jp

Key words: follicular lymphoma, CD44, tumor progression, immunohistochemistry, PCR thelial cells, and cells in the central nervous system $(3,4)$. It is encoded by a single gene, with alternative splicing providing the potential for multiple isoforms (5). The standard form of CD44 (CD44s) is ubiquitously expressed in epithelial and mesenchymal tissues, whereas the variant isoforms of CD44 $(\mathrm{CD} 44 \mathrm{v})$ generated by alternative RNA splicing are found in a restricted distribution (6-9). It has been shown that in a variety of human carcinomas (bladder, colon, breast, and stomach) there are certain overexpressed CD44v isoforms (10-14). Since differences in the expression of CD44v were detected between tumors with and without clinical evidence of metastasis formation, analysis of CD44v may serve as a prognostic and diagnostic marker (11).

Follicular lymphomas (FLs) constitute the majority of low-grade lymphomas, and often pursue an indolent course, but diffuse follicular center cell lymphomas display aggressive behavior and have a poor prognosis. Follicular lymphomas have either a follicular or diffuse growth pattern, and they frequently change from a follicular to a diffuse pattern over time (15).

Many studies of CD44 expression in non-Hodgkin's lymphoma (NHL) have been reported (16-21). Recently, upregulation of CD44v6 in NHLs was observed in highly aggressive lymphomas and CD44v6 expression could be shown to correlate with survival and the stage of the disease (22). In this study, we investigated the expression pattern of CD44 in 28 cases of follicular lymphomas (FLs) to elucidate the mechanisms of diffuse evolution of follicular lymphoma.

\section{Materials and methods}

Cases. Twenty-eight fresh lymph node specimens from 28 people with FLs were obtained from the Department of Pathology of Chiba University School of Medicine. Samples were snap-frozen in liquid nitrogen within $10 \mathrm{~min}$ of arrival at our pathology facilities, and kept frozen until use. Part of the samples was used for immunohistochemical staining. Nonneoplastic tissues were obtained from specimens surgically resected for the treatment of cancer or removed for nonneoplastic conditions ( 3 lymph nodes and 2 tonsils). The histological patterns of FLs were divided into four groups: i) intrafollicular (IF); ii) infiltrative (INF); iii) partially follicular (PF); and iv) minimally follicular (MF), according to the classification by Lukes and Collins (15). The study was 
conducted in accordance with the Helsinki Declaration. The University Ethics Committee approved this study and all patients provided written informed consent.

Immunohistochemistry. Tissue distribution of the different forms of CD44 was determined by streptavidin-biotin complex technique (Dakopatts Co., Inc., Denmark), in addition to identification of the immunophenotypes of the lymphomas. Cryostat sections were fixed in acetone for $10 \mathrm{~min}$, washed in PBS, and pre-incubated with normal rabbit serum. After pre-incubation, the sections were incubated for $1 \mathrm{~h}$ at room temperature or overnight at $4^{\circ} \mathrm{C}$ with the following primary antibodies (Abs): bcl-2 (Dakopatts Co., Inc.), murine monoclonal antibodies Bu52 (Binding Site Ltd., Birmingham, UK) and F10/44-2 (gift from Dr J. Farbre) against the common epitopes of CD44 molecules (CD44C), the Abs VFF-7 (Bender Med Systems, Vienna, Austria), 10 and 2C5 (R\&D Systems Europe Ltd., Abingdon, UK) against the V6 variant, and affinity purified polyclonal rabbit serum against the 20 aminoterminal peptides of exon 11 (CD44EX11). Before incubating the secondary biotinated $\mathrm{Ab}$ for 30 min (antimouse $\mathrm{F}(\mathrm{ab}) 2$; Dakopatts Co., Inc.), endogenous peroxidases were blocked with $0.3 \% \mathrm{H}_{2} \mathrm{O}_{2}$ in methanol. All antibodies were titrated for optimal staining results. For detection, a streptavidin-biotin peroxidase complex was used, and then the samples were developed using diaminobentidine- $\mathrm{HCl}$. The sections were counterstained with hematoxylin, dehydrated and coverslipped. In negative control experiments, BALB/c mouse ascites were applied to the sections in all cases.

Polymerase chain reaction (PCR)-Southern blotting. Total RNA was extracted from CD19 (clone 4G7, BectonDickinson, CA) positive cells from two cases of infiltrative FL (one mixed cell and one large cell type), and a case of partially follicular FL (large cell type), and two cases of minimally FL (one mixed and one large cell type). Total RNA was also extracted from CD19 and CD3 (clone SK7, Becton-Dickinson) positive cells from 3 cases of reactive lymph node. Selection of CD19 and CD3 positive cells was done from dispersed neoplastic or non-neoplastic lymph nodes using immunomagnetic Dynabeads 450 SH/MS IgG (Dynal A.S., Oslo, Norway) according to the manufacturer's instructions. Then, cDNA was synthesized with reverse transcriptase followed by amplification using an RNA PCR Kit (Perkin-Elmer Cetus, Norwalk, CT).

To determine the expression levels of different CD44s, semiquantitative PCR was employed. The conditions were $94^{\circ} \mathrm{C}$ for $1 \mathrm{~min}, 55^{\circ} \mathrm{C}$ for $1 \mathrm{~min}$, and $72^{\circ} \mathrm{C}$ for $2 \mathrm{~min}$. Negative controls, containing no template cDNA, were run with every batch. The amount of PCR products was calibrated by using the relative expression levels of human $B$-actin. Complementary DNA samples were initially amplified with $B$-actin specific primers (5' sense, 5'-CAGCCATGTACGTTGCTAT CCAG-3', and 3' anti-sense, 3'-ACTTCACACTGCACCTGT AGG-5'). These samples were electrophoresed on $1.2 \%$ agarose gel and transferred to Hybond $\mathrm{N}^{+}$nylon membranes (Amersham, UK) for hybridization with a [ $\left.{ }^{32} \mathrm{P}\right]$-labeled internal oligonucleotide probe, GAGCAAGAGATGGCCAC. After densitometric scanning of the actin products, the intensity balancing of all the samples was no higher than 3 -fold.
Table I. Characteristics of lymphoma cases.

\begin{tabular}{lc}
\hline Characteristics & No. of cases \\
\hline CD5 & $0 / 28$ \\
CD10 & $23 / 28$ \\
CD19 & $28 / 28$ \\
CD20 & $28 / 28$ \\
CD21 & $16 / 28$ \\
CD23 & $9 / 28$ \\
Bcl-2 & $26 / 28$ \\
bcl-2 rearrangement & $15 / 28$ \\
\hline
\end{tabular}

The same cDNA samples were amplified with CD44 primers. We devised the probes using information from the sequence of human CD44 DNA (23). The primers were P1 (458, 5'-GACACATATTGCTTCAATGCTTCAGC-3') and P2 (939, 3'-TAAGGTCTTACCGACGACTAGTAGAACC GTAG-5'), and a probe (S1 designed to anneal to the common portion of the CD44 molecules) was 478, 5'-CCTGAAGAA ATTGTACATCAGTCACAGAC-3' according to the sequence of CD44S.16. Exon-specific probes were the following: for exon 8, 5'-ACCACACCACGGGCCTTTGA-3', for exon 9, 5'-CACCCTCCCCTCATTCACCA-3', for exon 10, 5'-GGCAACAGATGGCATGAGGG-3', and for exon $11,5^{\prime}$-CATGGGACGAGGTCATCAAGC-3' as in the genomic structure of CD44 described by Screaton et al (5). Twenty-three cycles of PCR were chosen because this number had been determined to be in the linear range of amplification for both $B$-actin and CD44s. The blots were exposed for $5 \mathrm{~h}$ (standard CD44) and $24 \mathrm{~h}$ or longer (variant CD44), and then scanned with a bioimaging analyzer BAS-2000II (Fujix, Tokyo). For rehybridization, the blots were boiled in $0.5 \%$ SDS.

\section{Results}

Cases. The 28 FL cases showed marked variations in growth patterns. Six of them exhibited discrete follicular growth with lymphoid mantles and minimal infiltration of the interfollicular areas (intrafollicular FL). In 8 cases of infiltrative FL, the follicular structure was often destroyed, and the follicular center cells infiltrated to the interfollicular area. In 8 cases, areas of diffuse growth were observed (partial FL). In 2 cases, only a few follicles remained and a diffuse growth pattern was prominent (minimal FL). All cases of FL were positive for CD19 and CD20 as a B-cell marker, and negative for CD5 as a T-cell marker. The Bcl-2 protein was overexpressed in 22 cases of FL. Rearrangement of the bcl-2 gene was detected in 15 cases using a PCR method (Table I).

Immunohistochemistry of CD44. In the reactive lymph nodes, B lymphoid cells in the germinal center were CD44C negative, whereas the ones in the mantle zone were positive. $\mathrm{T}$ cells and macrophages both in the paracortex and follicles were positive for CD44C in the plasma membrane. Twenty-two of 28 cases of FLs showed positive reaction for CD44C (Table II). 
Hematoxylin and eosin

A

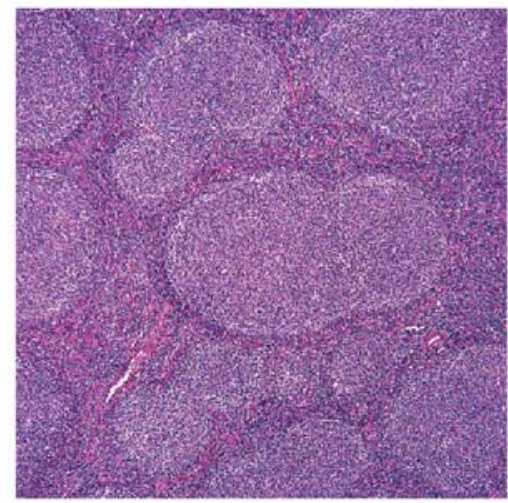

B

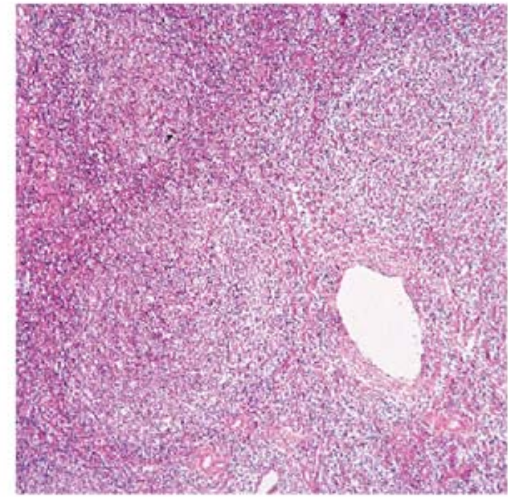

C
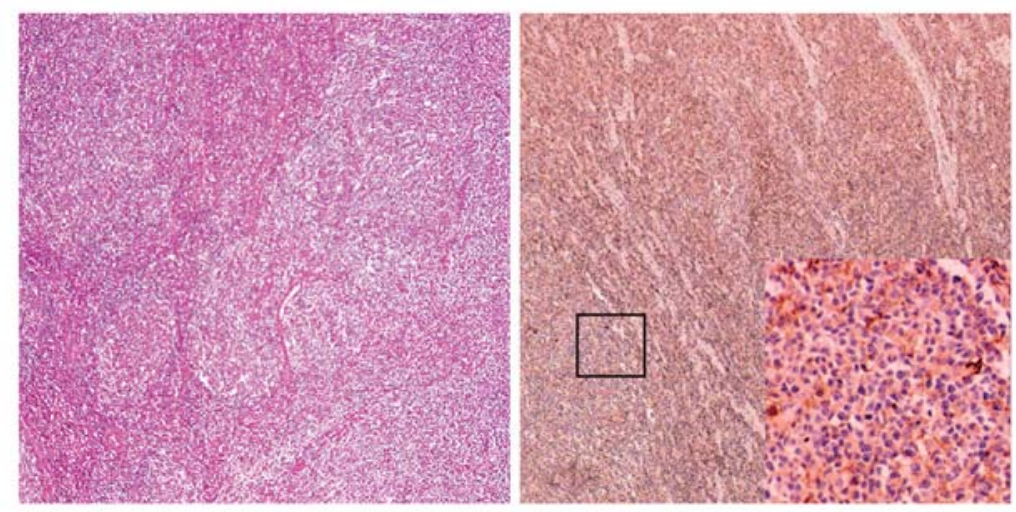

D

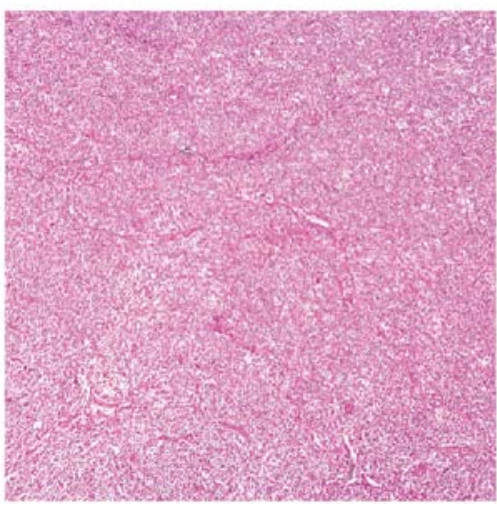

CD44C
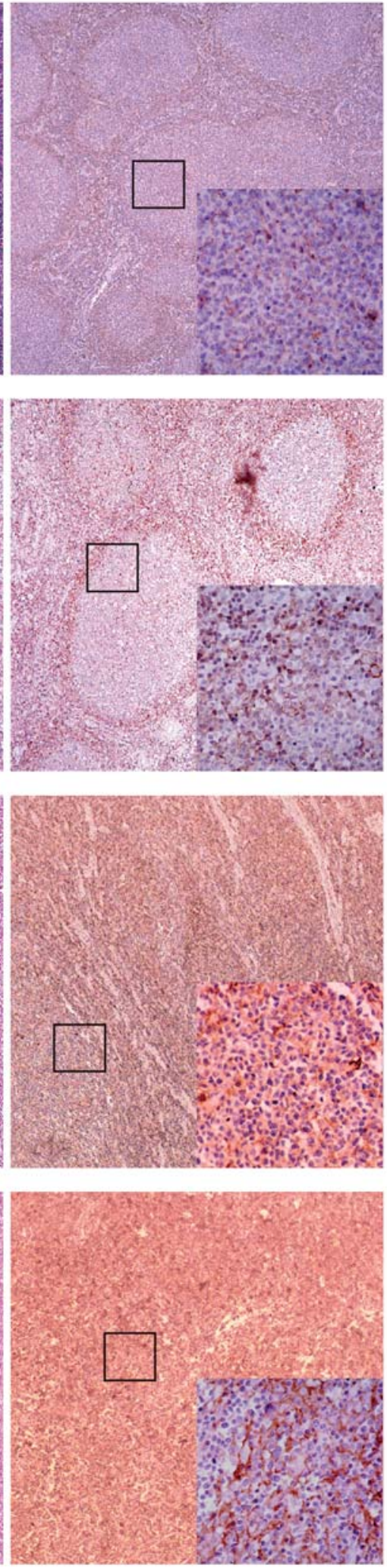

Figure 1. CD44 expression in follicular lymphoma. The lymphoma cells in the intrafollicular area were negative for CD44C (A). Infiltrative cells of interfollicular FL (B), partially follicular type (C) and minimally follicular type (D) were positive for CD44C. Inset, magnification of immunostaining of the CD44C.

In the three cases of intrafollicular FLs, the small cleaved cells were negative for CD44C (Fig. 2). In one case of intrafollicular FL, it was converted to infiltrative FL a year later without any treatment. The lymphoma cells in the converted case were CD44C positive (Fig. 1B). All cases of FLs with a diffuse pattern were positive for CD44C (Fig. 1C and D). 
Table II. Expression of CD44 in follicular lymphoma.

\begin{tabular}{lcccc}
\hline & \multicolumn{2}{c}{ Immunohistochemistry } & \multicolumn{2}{c}{ PCR-Southern } \\
\cline { 2 - 4 } Subtypes & Localization & CD44C & & CD44s \\
\hline Reactive lymph nodes & GC & $0 / 5$ & $3 / 3$ & $0 / 3$ \\
Follicular lymphoma & & & & nd \\
$\quad$ Intrafollicular & IF & $0 / 6$ & nd & nd \\
Infiltrative & IF & $0 / 8$ & $2 / 2$ & nd \\
Partially follicular & IA & $8 / 8$ & $1 / 1$ & $2 / 2$ \\
Minimally follicular & DA & $12 / 12$ & $2 / 2$ & $2 / 2$ \\
Total & DA & $2 / 2$ & 5 & 5 \\
\hline
\end{tabular}

aMolecular weight bands higher than 482 bp with the exon 10 or 11 probes. GC, germinal center; IF, intrafollicular area; IA, infiltrative area; DA, diffuse area; nd, not done.

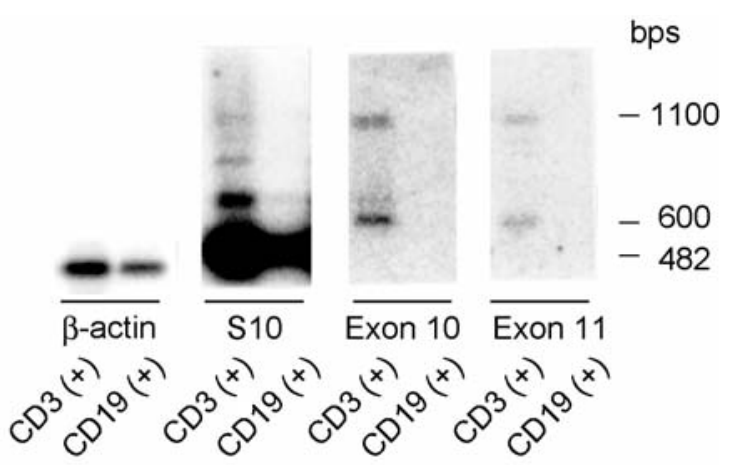

Figure 2. Expression of CD44 transcripts in reactive lymph nodes. The amplified $ß$-actin PCR products are found at 567 for 23 cycles using oligonucleotide primers. CD3 positive cells from a reactive lymph node (lane 1) showed four bands at 482, 700, 900 and 1100 bp with the S1 probe, two bands at 609 and $1100 \mathrm{bp}$ with the exon 10 probe, and two bands at 612 and $1100 \mathrm{bp}$ with the exon 11 probe. CD19 positive cells from reactive lymph nodes (lane 2) showed only a 482 bp band with the S1 probe and no variant transcripts with the exon 10 and 11 probes.
CD44 transcripts. Amplification of the region spanning the primers $\mathrm{P} 1$ and $\mathrm{P} 2$ is predicted to generate a product of $\sim 482$ bp from cDNAs encoding CD44s, and 878 bp from cDNAs encoding the epithelial variant of CD44 (CD44E). With up to 34 cycles of PCR, no CD44 transcripts were detected in cDNAs prepared from the pre-B cell line NALM-6, and thus it was used as a negative control in the following experiments.

The cDNAs amplified from CD19 cells selected from reactive lymph nodes yielded a $482 \mathrm{bp}$ band with the $\mathrm{S} 1$ probe for detection of the CD44 common region, but no transcripts containing exons 10 and 11 were amplified (Fig. 2, lane 2). The transcripts amplified from the cDNA of CD3-positive lymphocytes from the reactive lymph nodes included four different sizes of transcripts with the common probe S1 (482, 700,900 , and $1100 \mathrm{bp}$ bands). Two different sizes of transcripts were detected (609 and $1100 \mathrm{bp}$ ) with the exon 10 probe, and 612 and 1100 bp bands with the exon 11 probe

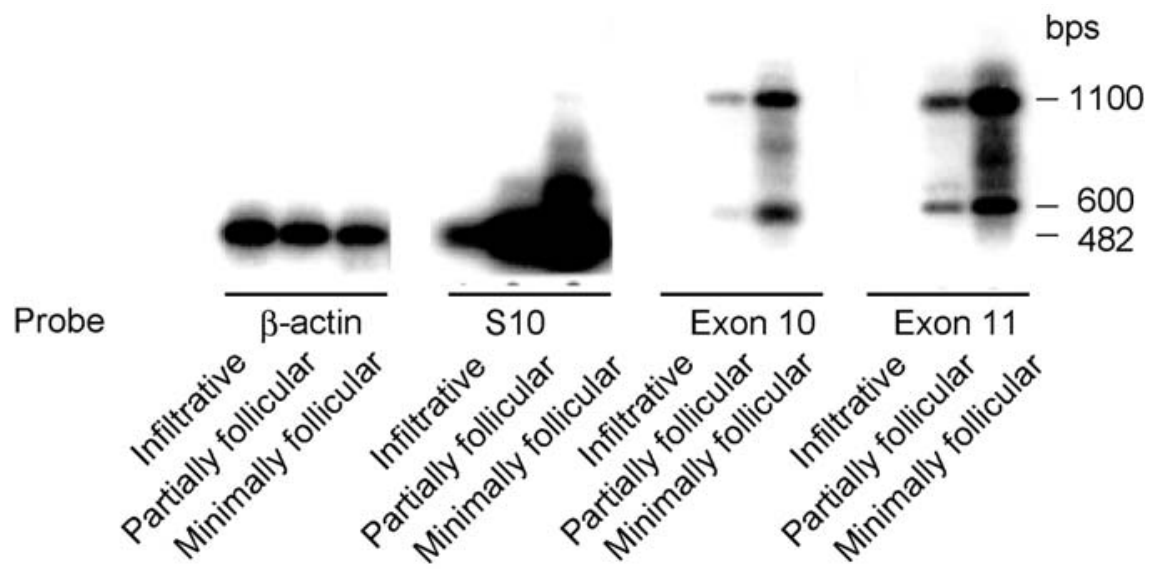

Figure 3. Expression of CD44 transcripts in lymphomas. The amplified ß-actin PCR products are found at 567 for 23 cycles using oligonucleotide primers. Lane 1, CD19 selected cells from infiltrative FL; lane 2, CD19 selected cells from partially FL; lane 3, CD19 selected cells from minimally FL. With the $\mathrm{S} 1$ probe, lane 1 showed a major $482 \mathrm{bp}$ band. Variant transcripts are found at $609,900,1100 \mathrm{bp}$ with the exon 10 probe and at 612,900 and $1250 \mathrm{bp}$ with the exon 11 probe in lane 2 and 3. 
(Fig. 2, lane 1). With the exon 8 and 9 probes, signals were not observed.

The cDNAs amplified from CD19 positive cells selected from two cases of infiltrative FL yielded only a 482 bp band without variant transcripts (Fig. 3, lane 1). CD19 selected cells from partially FL showed a single 482 bp band with the S1 probe and both a 609 and 1100 bp band with the exon 10 probe or the exon 11 probe (Fig. 3, lane 2). In two cases of minimally FL, the amplification of the cDNAs using the same combinations of oligonucleotides resulted in a 482 bp band with the $\mathrm{S} 1$ probe, 609,900 and $1000 \mathrm{bp}$ bands with the exon 10 probe, 612, 9001100 , and 1250 bp bands with the exon 11 probe (Fig. 3, lane 3). There were also a few faint cDNA products between the two major variant transcripts. No signals were found using the exon 8 or 9 probes in the materials examined (data not shown).

A summary of the expression patterns of the CD44 proteins and mRNAs is given in Table II. The results demonstrate that the expression of CD44s and CD44 variants containing exon 10 and 11 were upregulated according to the diffuse evolution of the follicular lymphoma.

\section{Discussion}

In most follicular lymphomas, the constitutive expression of Bcl-2 confers longevity to follicular B-cells, resulting in their accumulation through the lymphoid system $(24,25)$. Secondary genetic changes, such as the mutation of p53 or the accumulation of the c-myc protein are required for malignant transformation and histological progression from a follicular pattern to a diffuse pattern (24-26).

Adhesion proteins including CD44 play pivotal roles in tumor progression and metastasis. CD44 is expressed as several different isoforms, achieved by the alternative mRNA splicing of eleven variant exons (27). It has been demonstrated that CD44 is expressed in diffuse large Bcell lymphomas and the expression of CD44 is correlated with their aggressive behavior. The expression of exon 10 containing transcripts has been found in the intermediate and high grade categories of diffuse B-cell lymphomas $(28,29)$. In the present study, lymphoma cells from the cases of intrafollicular type cancers did not express CD44. Cells from the infiltrative lymphoma showed the expression of CD44s. The results suggest that CD44s is involved in the invasion of lymphoma cells as in the other epithelial neoplasm.

Tumor progression could be acquired step by step through mutation and selection induced by pleiotropic control proteins for various genes (30). The present study suggests that genetic alterations during tumor progression of the germinal center cell tumor induce the expression of CD44s which are later accompanied by high molecular weight variant forms. Our findings are quite consistent with the reported observation that the activated oncogene c-Ha-ras induces CD44 promoter activity and leads to increased levels of CD44s accompanied by the appearance of alternatively spliced RNAs (31). Therefore, the elucidation of the regulatory mechanism of the serial genetic changes of CD44 expression in lymphoma cells may lead toward approaches for suppressing tumor progression and developing novel cancer treatments.

\section{Acknowledgments}

We thank K. Azuma and T. Fujino for technical help, Dr J. Farbre (East Grinstead Medical Research Trust, Sussex, UK) for providing a monoclonal antibody (F10/44-2) and Grants-in-Aid for Scientific Research no. 02256202 and no. 05670188 (to K.H.) from the Ministry of Education, Science and Culture of Japan.

\section{References}

1. Idzerda RL, Carter WG, Nottenburg C, Wayner EA, Gallatin WM and St John T: Isolation and DNA sequence of a cDNA clone encoding a lymphocyte adhesion receptor for high endothelium. Proc Natl Acad Sci USA 86: 4659-4663, 1989.

2. Neame SJ and Isacke CM: Phosphorylation of CD44 in vivo requires both Ser323 and Ser325, but does not regulate membrane localization or cytoskeletal interaction in epithelial cells. EMBO J 11: 4733-4738, 1992.

3. Lesley J, He Q, Miyake K, Hamann A, Hyman R and Kincade PW: Requirements for hyaluronic acid binding by CD44: a role for the cytoplasmic domain and activation by antibody. J Exp Med 175: 257-266, 1992.

4. Stamenkovic I, Aruffo A, Amiot M and Seed B: The hematopoietic and epithelial forms of CD44 are distinct polypeptides with different adhesion potentials for hyaluronate-bearing cells. EMBO J 10: 343-348, 1991.

5. Screaton GR, Bell MV, Jackson DG, Cornelis FB, Gerth U and Bell JI: Genomic structure of DNA encoding the lymphocyte homing receptor CD44 reveals at least 12 alternatively spliced exons. Proc Natl Acad Sci USA 89: 12160-12164, 1992.

6. Brown TA, Bouchard T, St John T, Wayner E and Carter WG: Human keratinocytes express a new CD44 core protein (CD44E) as a heparan-sulfate intrinsic membrane proteoglycan with additional exons. J Cell Biol 113: 207-221, 1991.

7. Goldstein LA, Zhou DF, Picker LJ, Minty CN, Bargatze RF, Ding JF and Butcher EC: A human lymphocyte homing receptor, the hermes antigen, is related to cartilage proteoglycan core and link proteins. Cell 56: 1063-1072, 1989.

8. Heider KH, Dammrich J, Skroch-Angel P, Muller-Hermelink HK, Vollmers HP, Herrlich P and Ponta H: Differential expression of CD44 splice variants in intestinal- and diffuse-type human gastric carcinomas and normal gastric mucosa. Cancer Res 53: 4197-4203, 1993 .

9. Heider KH, Hofmann M, Hors E, van den Berg F, Ponta H, Herrlich P and Pals ST: A human homologue of the rat metastasis-associated variant of CD44 is expressed in colorectal carcinomas and adenomatous polyps. J Cell Biol 120: 227-233, 1993

10. Charpin C, Garcia S, Bouvier C, Devictor B, Andrac L, Choux R, Lavaut MN and Allasia C: Automated and quantitative immunocytochemical assays of CD44v6 in breast carcinomas. Hum Pathol 28: 289-296, 1997.

11. Matsumura Y and Tarin D: Significance of CD44 gene products for cancer diagnosis and disease evaluation. Lancet 340: 1053-1058, 1992.

12. Mueller JD, Heider KH, Oberhuber G, Mueller E, Bethke B, Stolte $M$ and Hofler H: Comparison of CD44 expression in early colorectal carcinomas of the de novo and ex adenoma types. Virchows Arch 433: 407-414, 1998.

13. Mulder JW, Kruyt PM, Sewnath M, Oosting J, Seldenrijk CA, Weidema WF, Offerhaus GJ and Pals ST: Colorectal cancer prognosis and expression of exon-v6-containing CD44 proteins. Lancet 344: 1470-1472, 1994.

14. Wielenga VJ, Heider KH, Offerhaus GJ, Adolf GR, van den Berg FM, Ponta H, Herrlich P and Pals ST: Expression of CD44 variant proteins in human colorectal cancer is related to tumor progression. Cancer Res 53: 4754-4756, 1993.

15. Lukes RJ and Collins DR: Follicular center cell lymphomas, including Burkitt's lymphoma. Armed Forces Institute of Pathlogy, Washingtong DC, 1992.

16. Chen C, Chang MC, Hsieh RK, Chang YF, Lin J and Tsan KW: Activation of CD44 facilitates DNA repair in T-cell lymphoma but has differential effects on apoptosis induced by chemotherapeutic agents and ionizing radiation. Leuk Lymphoma 46: 1785-1795, 2005. 
17. Tzankov A, Pehrs AC, Zimpfer A, Ascani S, Lugli A, Pileri S and Dirnhofer S: Prognostic significance of CD44 expression in diffuse large B cell lymphoma of activated and germinal centre B cell-like types: a tissue microarray analysis of 90 cases. J Clin Pathol 56: 747-752, 2003.

18. Akisik E, Bavbek S and Dalay N: CD44 variant exons in leukemia and lymphoma. Pathol Oncol Res 8: 36-40, 2002.

19. Aguilera NS, Chu WS, Andriko JA and Abbondanzo SL: Expression of CD44 (HCAM) in small lymphocytic and mantle cell lymphoma. Hum Pathol 29: 1134-1139, 1998.

20. Bartolazzi A, Jackson D, Bennett K, Aruffo A, Dickinson R, Shields J, Whittle N and Stamenkovic I: Regulation of growth and dissemination of a human lymphoma by CD44 splice variants. J Cell Sci 108 (Pt 4): 1723-1733, 1995

21. Horst E, Meijer CJ, Radaszkiewicz T, Ossekoppele GJ, Van Krieken JH and Pals ST: Adhesion molecules in the prognosis of diffuse large-cell lymphoma: expression of a lymphocyte homing receptor (CD44), LFA-1 (CD11a/18), and ICAM-1 (CD54). Leukemia 4: 595-599, 1990.

22. Hofmann M, Rudy W, Zoller M, Tolg C, Ponta H, Herrlich P and Gunthert U: CD44 splice variants confer metastatic behavior in rats: homologous sequences are expressed in human tumor cell lines. Cancer Res 51: 5292-5297, 1991

23. Stamenkovic I, Amiot M, Pesando JM and Seed B: A lymphocyte molecule implicated in lymph node homing is a member of the cartilage link protein family. Cell 56: 1057-1062, 1989.

24. Lundgren E, Roos G, Nordenson I, Wahlin A and Lind J: Multiple DNA rearrangements in the BCL2 region in a patient with follicular lymphoma. Genes Chromosomes Cancer 3: 390-393, 1991.
25. Price CG, Tuszynski A, Watt SM, Murdoch SJ, Lister TA and Young BD: Detection of additional JH/BCL2 translocations in follicular lymphoma. Leukemia 5: 548-554, 1991.

26. Lo Coco F, Gaidano G, Louie DC, Offit K, Chaganti RS and Dalla-Favera R: p53 mutations are associated with histologic transformation of follicular lymphoma. Blood 82: 2289-2295, 1993.

27. Lesley J and Hyman R: CD44 structure and function. Front Biosci 3: D616-D630, 1998.

28. Koopman G, Heider KH, Horst E, Adolf GR, van den Berg F, Ponta H, Herrlich P and Pals ST: Activated human lymphocytes and aggressive non-Hodgkin's lymphomas express a homologue of the rat metastasis-associated variant of CD44. J Exp Med 177: 897-904, 1993.

29. Moller P, Eichelmann A, Mechtersheimer G and Koretz K: Expression of beta 1-integrins, H-CAM (CD44) and LECAM-1 in primary gastro-intestinal B-cell lymphomas as compared to the adhesion receptor profile of the gut-associated lymphoid system, tonsil and peripheral lymph node. Int J Cancer 49: 846-855, 1991

30. Hill RP: Metastasis. McGrow-Hill, New York, 1992.

31. Hofmann M, Rudy W, Gunthert U, Zimmer SG, Zawadzki V, Zoller M, Lichtner RB, Herrlich P and Ponta H: A link between ras and metastatic behavior of tumor cells: ras induces CD44 promoter activity and leads to low-level expression of metastasisspecific variants of CD44 in CREF cells. Cancer Res 53: 1516-1521, 1993. 